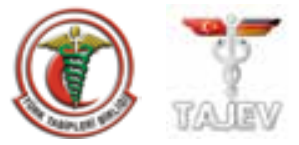

\title{
Cervical premalignant lesions and their management
}

\author{
Faruk M. Köse, Murat M. Naki \\ Department of Obstetrics and Gynecology, Bahçeşehir University Faculty of Medicine, Istanbul, Turkey
}

\begin{abstract}
Cervical cancer is the tenth most common cancer in women in developed countries that have national screening programs, while it is in the second line in underdeveloped countries. According to Ministry of Health registry data, cervical cancer is the eighth most common cancer among female cancers in Turkey. Today, the most effective screening for cervical cancer is to obtain smears from the cervix. Therefore, periodic screening programs are of great importance in identifying preinvasive lesions to prevent their progression to invasive cancer. Today, with the use of human papilloma virus (HPV) vaccine, screening programs have brought new insights into the prevention of cervical cancer. Management of preinvasive lesions has to be known by each obstetrics and gynecology specialist. Redundant procedures and treatments can be avoided by directing patients correctly at this step. Cancer phobia should not be created. Ablative or destructive treatments should not be done without histological diagnosis; hysterectomy, which has an equal risk of recurrence, should not be recommended.
\end{abstract}

(J Turk Ger Gynecol Assoc 2014; 15: 109-21)

Key words: Cervix, preinvasive lesions, management, human papilloma virus

Received: 17 October, 2013

Accepted: 17 October, 2013

\section{Introduction}

Cervical intraepithelial lesions or invasive tumors are caused by infection with human papilloma virus (HPV). More than 100 different strains of HPV are known today, and those considered of high risk are involved in the etiology of cancer. About $99.7 \%$ of HPV infections are sexually transmitted and are rarely transmitted from mother to the neonate through an ascending route during delivery.

Every 2 minutes, a woman dies because of cervical cancer worldwide, which is the leading cause of deaths in women; 52,000 new cervical cancer cases are seen annually in the European Union, and 27,000 people die annually due to this disease (1). Based on these findings, cervical cancer is the second most common cause of cancer deaths after breast cancer among women in the European Union. Cervical cancer is the tenth most common cancer in women in developed countries that have national screening programs, while is in the second line in underdeveloped countries. According to Ministry of Health registry data, cervical cancer is the eighth most common cancer among female cancers in our country (2).

Today, the most effective screen for cervical cancer is to obtain smears from the cervix. Therefore, periodic screening programs are of great importance in identifying preinvasive lesions to prevent their progression to invasive cancer. Today, with the use of HPV vaccine, screening programs have brought new insights in to the prevention of cervical cancer. Management of preinvasive lesions has to be known by each obstetrics and gynecology specialist. Redundant procedures and treatments can be avoided by directing patients correctly at this step. Cancer phobia has not been created. Ablative or destructive treatments should not be done without histological diagnosis; hysterectomy, which has an equal risk of recurrence, should not be recommended.

\section{Relation between HPV and Cervical Cancer}

Human papillomavirus belongs to the Papillomaviridae family. To date, more than 100 different HPV types have been identified. This virus is a small (8 kilobases), double-stranded DNA virus that infects skin and mucosal epithelial surfaces, leading to proliferative lesions, and is specific to species. So, HPV infects only humans. The causal relation with cancer is more pronounced than the relation between smoking and cancer. Currently, the high-risk group is identified during HPV testing, and its typing can be performed, as needed. The most effective methods for HPV testing are hybrid-capture (HC) II assay and polymerase chain reaction (PCR). Both methods detect whether there exist an average of 13 high-risk HPV types or not. An HPV-positive result of these tests means that there exists at least one of the high-risk HPV types, and an HPV-negative result means that a high-risk HPV type does not exist. The classification of HPV types according to risk stratification is presented in Table 1.

Squamous cell disorders are the most prominent pathology after HPV infection of the cervix. Glandular cell abnormalities are rarely seen. Spontaneous regression of low-grade squamous intraepithelial lesion (LGSIL) or HPV infection is noted in $60 \%$ of cases. Only about $15 \%$ of these patients appear as a high-grade squamous intraepithelial lesion (HGSIL) in the 
Table 1. HPV subtype classification

\begin{tabular}{|l|l|}
\hline High-risk & $16,18,45,31,33,52,58,35,59,56,51,39,68,73,82$ \\
\hline Moderate-risk & $26,53,66$ \\
\hline Mild-risk & $6,11,40,42,43,44,54,61,70,72,81, \mathrm{CP} 6108$ \\
\hline HPV: human papilloma virus \\
\hline
\end{tabular}

Table 2. Prognosis of untreated CIN lesions

\begin{tabular}{|l|c|c|c|c|}
\hline & Regression & Persistence & $\begin{array}{c}\text { Progression } \\
\text { to CIN 3 }\end{array}$ & $\begin{array}{c}\text { Invasive } \\
\text { Cancer }\end{array}$ \\
\hline CIN 1 & $60 \%$ & $40 \%$ & $10 \%$ & $1 \%$ \\
\hline CIN 2 & $40 \%$ & $40 \%$ & $20 \%$ & $5 \%$ \\
\hline CIN 3 & $33 \%$ & & & $>12 \%$ \\
\hline \multicolumn{4}{l}{ CIN: cervical intraepithelial neoplasia } \\
\hline
\end{tabular}

presence of cofactors within 3-4 years. These cofactors include high-risk HPV types; cigarette smoking; immunosuppression; cervical infections, such as chlamydia and Herpes simplex virus (HSV); oral contraceptive pill use; multiparity; and genetic factors. Spontaneous regression rates decrease after HGSIL development, and $30-70 \%$ of these cases progress to invasive cancer within approximately 10 years. In other words, $15 \%$ of women with HPV develop cervical intraepithelial neoplasia (CIN) within 7 years. Regression and progression rates of CIN are shown in Table 2. Development of invasive cancer is established at a rate of $1-3 \%$ after high-risk HPV transmission, and the required time period is approximately $25-40$ years.

Human papilloma virus testing was found to be positive in $96.6 \%$ of patients with cervical cancer. HPV types that are mostly associated with the development of cervical squamous cancer are HPV 16 (53.5\%), HPV 18 (17.2\%), HPV 45 (6.2\%), and HPV 31 (2.9\%). These rates and types other than HPV 16 and HPV 18 can differ by countries. However, HPV 16 and HPV 18 are identified as being mostly associated with $70.7 \%$ of cervical cancers. HPV 18 is mostly associated with cervical adenocarcinoma. In a retrospective study evaluating data from 10,575 patients with invasive cervical cancer conducted by de Sanjose et al. (3), it was reported that HPV 16 and HPV 18 were positive in $71 \%$ of patients. In the same study, HPV 16, HPV 18, and HPV 45 were identified as positive in $94 \%$ of cervical adenocarcinoma cases. In the study of Usubütün et al. (4), they identified HPV types in cervical cancer in our country, and they found the ratios of types as follows: HPV 16 was $64.7 \%$, HPV 18 was 9.9\%, HPV 45 was 9.9\%, HPV 31 was $3 \%$, and HPV 33 was $2.2 \%$.

\section{A. HPV testing}

Human papilloma virus (HPV) is believed to initiate tumorigenesis in cervical carcinoma. HPV is also associated with some anal, vaginal, vulvar, oral, and skin cancers other than cervix. It is suggested to be associated with $4 \%$ of all cancers throughout the body (5). According to western society statistics, $50-80 \%$ of women are infected with HPV at least once in their lives (6). While the infection rate is higher in young patients ( $<25$ years), it declines in the 30 s and 40 s and shows a slight increase in the postmenopausal period $(7,8)$. Oncogenic HPV type is present in $10 \%$ of the $20-65$-year-old population. The latent infection prevalence is $8-15 \%$ (9). Transient HPV infection is not of importance in cancer development, whereas HPV DNA positivity is a risk factor for cervical cancer (10).

Since colposcopy is recommended for HPV 16-positive cases, HPV tests specific for HPV 16 and HPV 18 are available in addition to oncogenic HPV testing. For women with ASC-US cytology and (-) HPV result, colposcopy and biopsy are unnecessary, and follow-up cytology at regular intervals is acceptable. If HPV is positive, immediate colposcopy should be performed as a secondary management. A positive $(+)$ test result in a patient with ASC-US smear suggests that the patient has HGSIL at more than $90 \%$ probability. The negative (-) predictive value of the testing is higher than $90 \%(11,12)$. The sensitivity of HPV DNA testing in HGSIL HPV $(+)$ patients is $98 \%$.

Also, $20-40 \%$ of precancerous lesions can not be detected by colposcopy, even by the most experienced specialist. HPV testing in this patient group will be a guide in patient follow-up. While a negative test result supports the lack of detection of lesion by colposcopy, a positive test result will suggest the presence of risk and show that the colposcopy result is a false negative (13).

\section{Abnormal Cervical Smear Management Squamous cell abnormalities}

A. Unsatisfactory cytology

When all cytological methods are included, the probability of unsatisfactory cytology is less than $1 \%$. This result is unreliable in the detection of epithelial abnormalities $(14,15)$. The most common reason for this unsatisfactory cytology is the insufficient squamous cell count (16). Management of unsatisfactory cytology is presented in Figure 1.

\section{B. Cytology reported as negative but with absent or insufficient endocervical and transformation zone}

Cytology that is reported as negative but with an absent or insufficient endocervical and transformation zone has adequate cellularity for interpretation but lacks endocervical or metaplastic cells, suggesting that the squamocolumnar junction may not have been adequately sampled. Recent publications report that this cytological abnormality has ranged from $10 \%$ to $20 \%$ and is higher in older women $(17,18)$. The management of this cytological abnormality, which was recently recommended for early repeat cytology, has changed as indicated in Figure 2.

\section{Negative cytology with a positive HPV test}

Recently, co-testing is the preferred screening strategy for women aged 30-64 years and is not indicated for younger women (19). Despite negative cytology, women with HPV are at higher risk for later CIN 3 than women with negative HPV tests (20). Management of cases with negative cytology but with a positive HPV test is presented in Figure 3.

\section{D. $\boldsymbol{A S C}$-US}

Atypical squamous cell (ASC) lesions that are unclassified and with undetermined significance are called ASC-US. ASC-US terminology was not approved in a Bethesda 2001 consensus meeting and has been modified. Accordingly, under the head- 


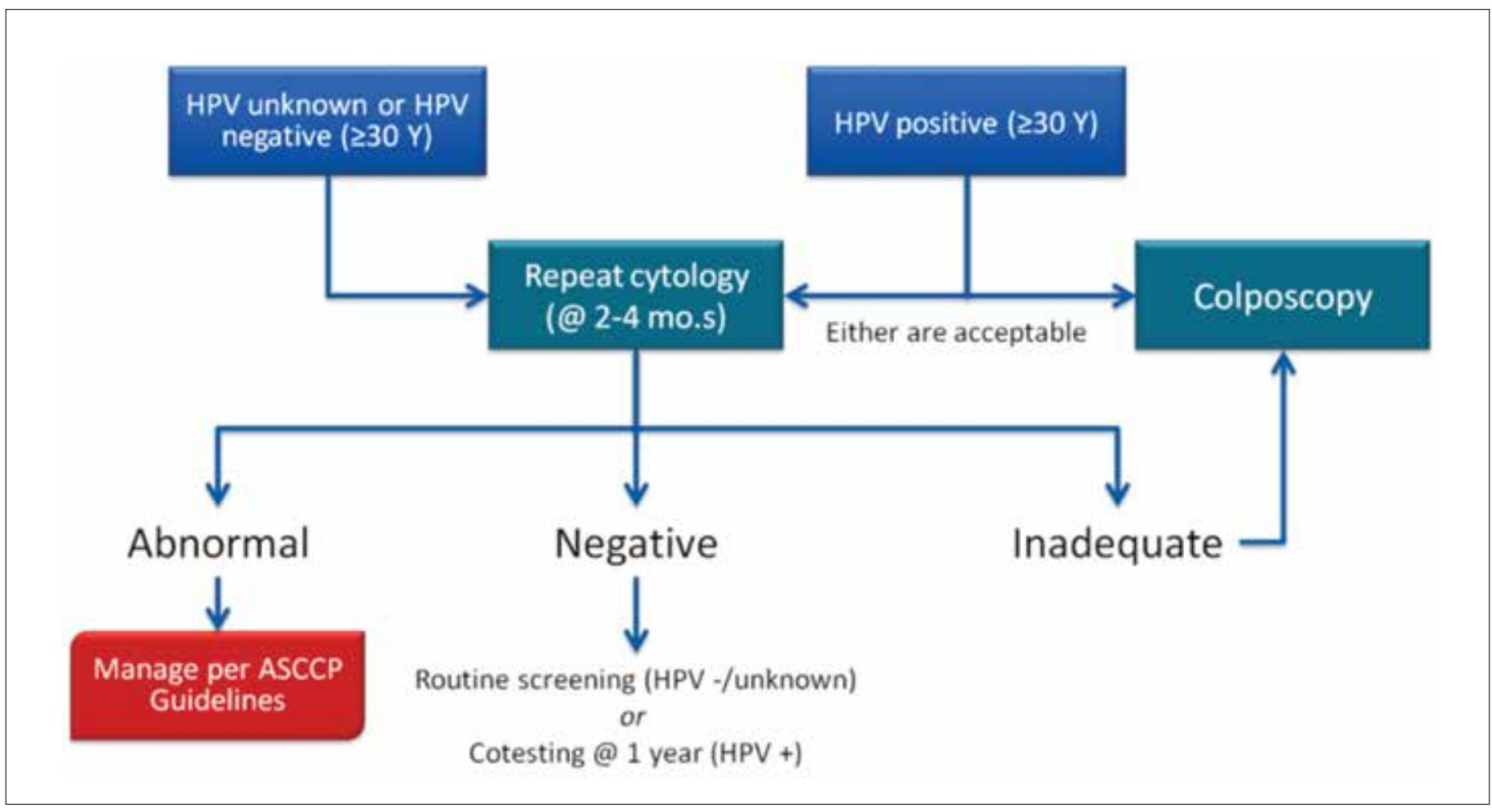

Figure 1. Management of unsatisfactory cytology

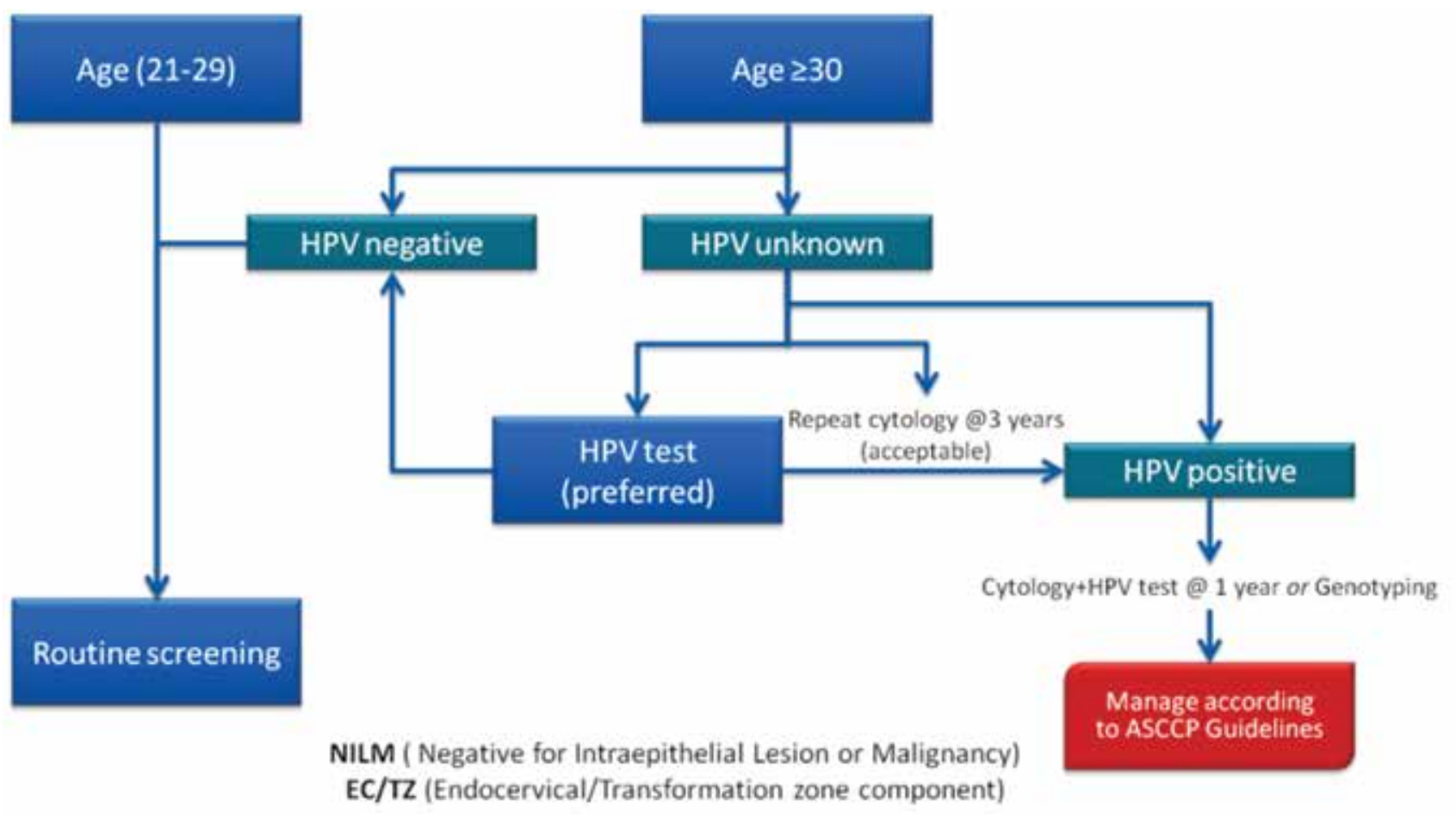

Figure 2. Management of cytology reported as negative but with absent or insufficient endocervical and transformation zone 


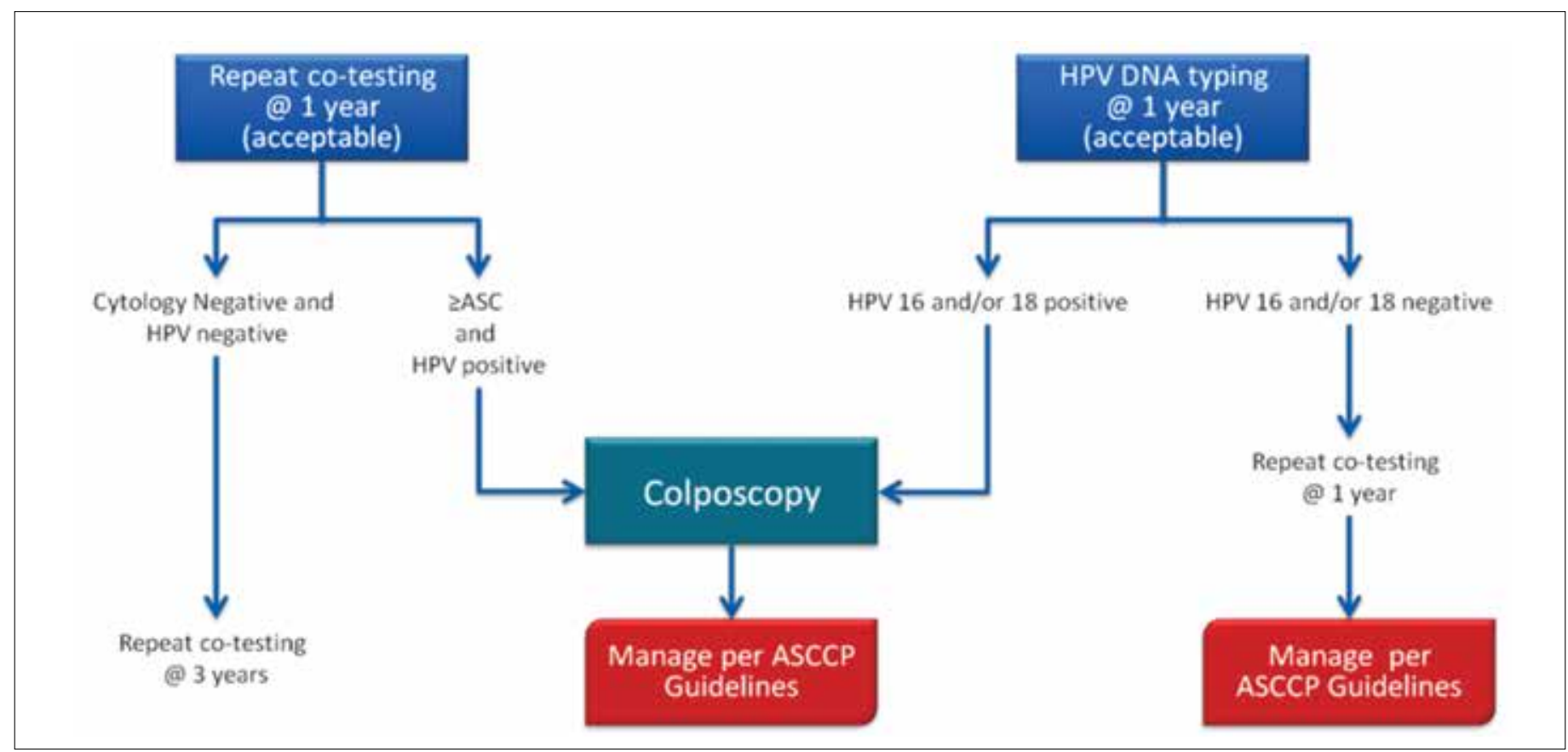

Figure 3. Management of HPV-positive cases with negative cytology

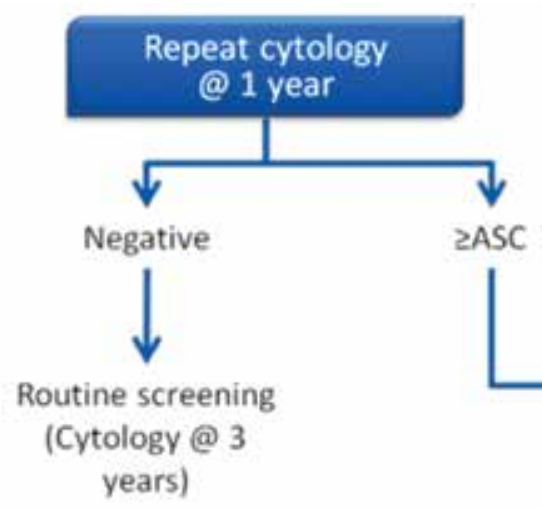

\section{* Management options may vary if the} women is pregnant or ages 21-24

\section{Figure 4. ASC-US management}

ing of atypical squamous cells, ASC-US and atypical squamous cells can not exclude HGSIL (ASC-H) and will be reported by differentiating malignancy potential. There are two pathways for follow-up of ASC-US. One is to repeat smear testing after 1 year; the second is to test for high-risk HPV.

Yearly follow-up route has the advantages of low cost, easy application, and common use, but $30 \%$ of HGSIL can be missed. HPV testing is more likely to diagnose HGSIL and is highly reliable, with $95 \%$ negative predictive value. High sensitivity in colposcopy can be achieved among referred cases. However, it is expensive and uncommon. Low-cost reagents that can determine the type have been marketed since 2001. Several studies about ASC-US have been published recently. The consensus for the ASC-US method algorithm is shown in Figures 4 and 5.

\section{E. LGSIL}

When minimal cytological abnormalities are detected in a woman, HPV DNA testing should be performed if possible. If 


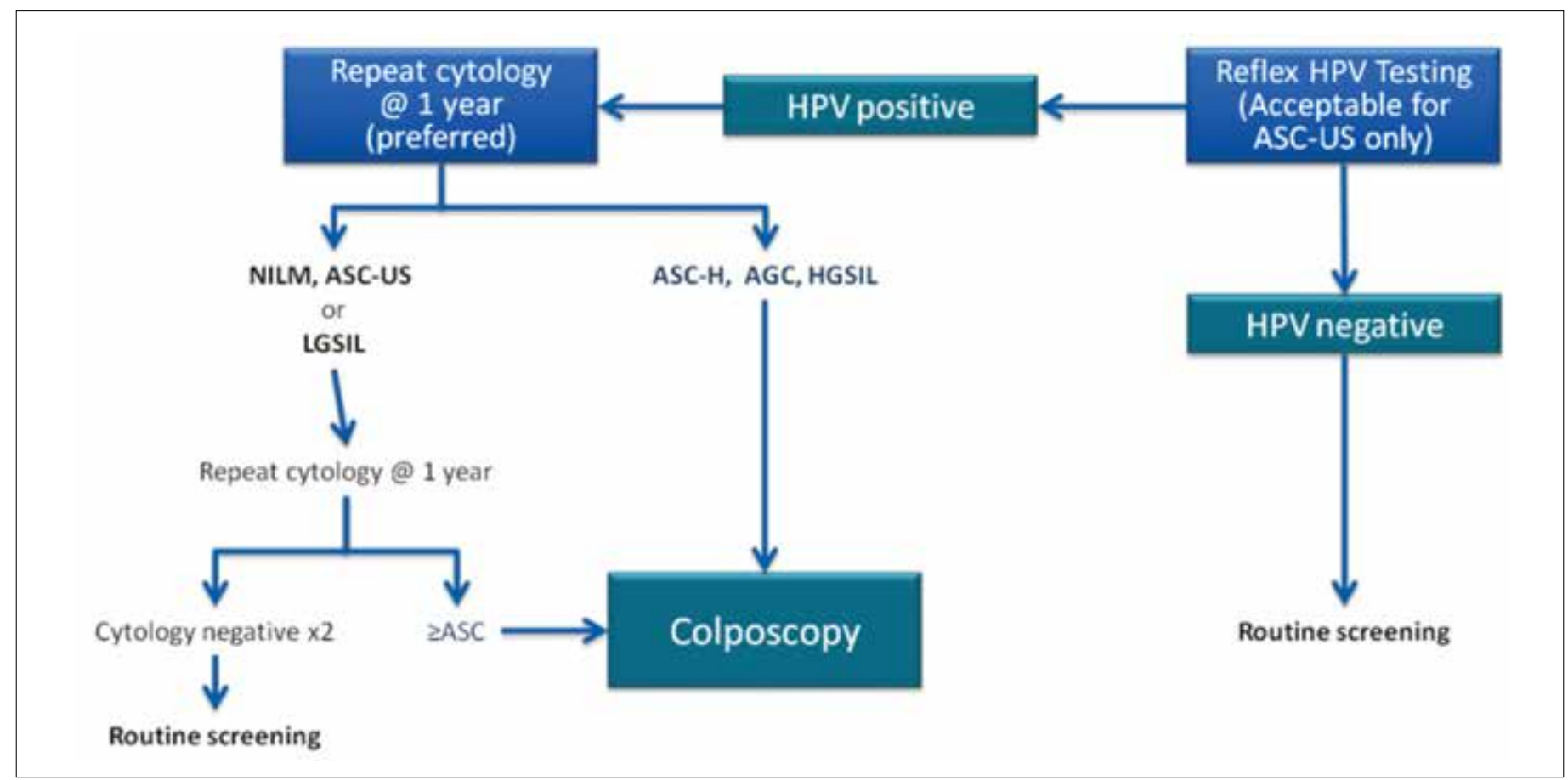

Figure 5. Management ASC-US and LSIL for ages between 21-24 years

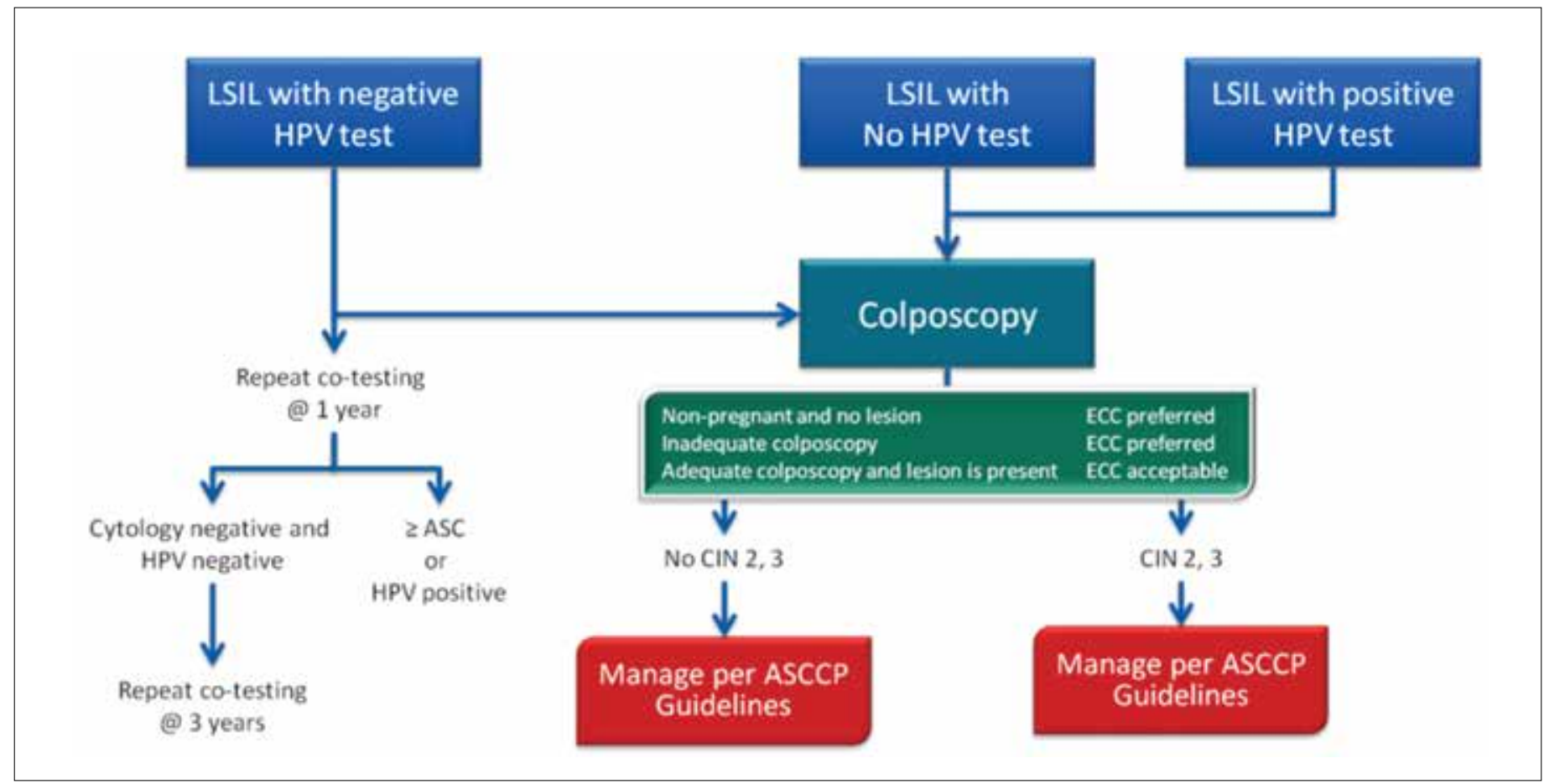

Figure 6. LSIL management

HPV DNA testing is negative, patient should be followed up with yearly control. If HPV DNA testing is positive, patients are referred for colposcopy and managed according to the results. If HPV DNA testing is not possible, colposcopic examination will be performed; if it is normal, the patient will be called periodically with yearly controls until the smear becomes normal. If an abnormal lesion is detected by colposcopy, immediate treatment is necessary. The related algorithm is presented in Figures 5-7.

\section{E. $A S C-H$}

ASC-H confers higher risk for CIN 3 over time than ASC-US or LGSIL. Reflex HPV testing is not recommended in ASC-H due to high HPV prevalence. In addition, the 5-year cancer risk among 


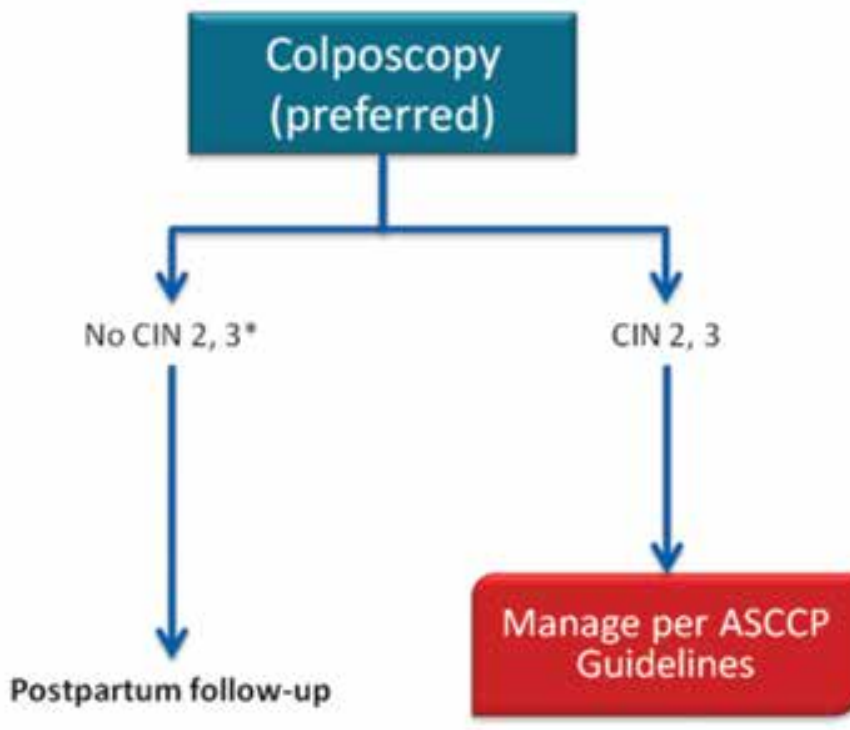

\section{Defer Colposcopy \\ (until at least 6 \\ weeks postpartum)}

Postpartum follow-up

Figure 7. LSIL management in pregnancy

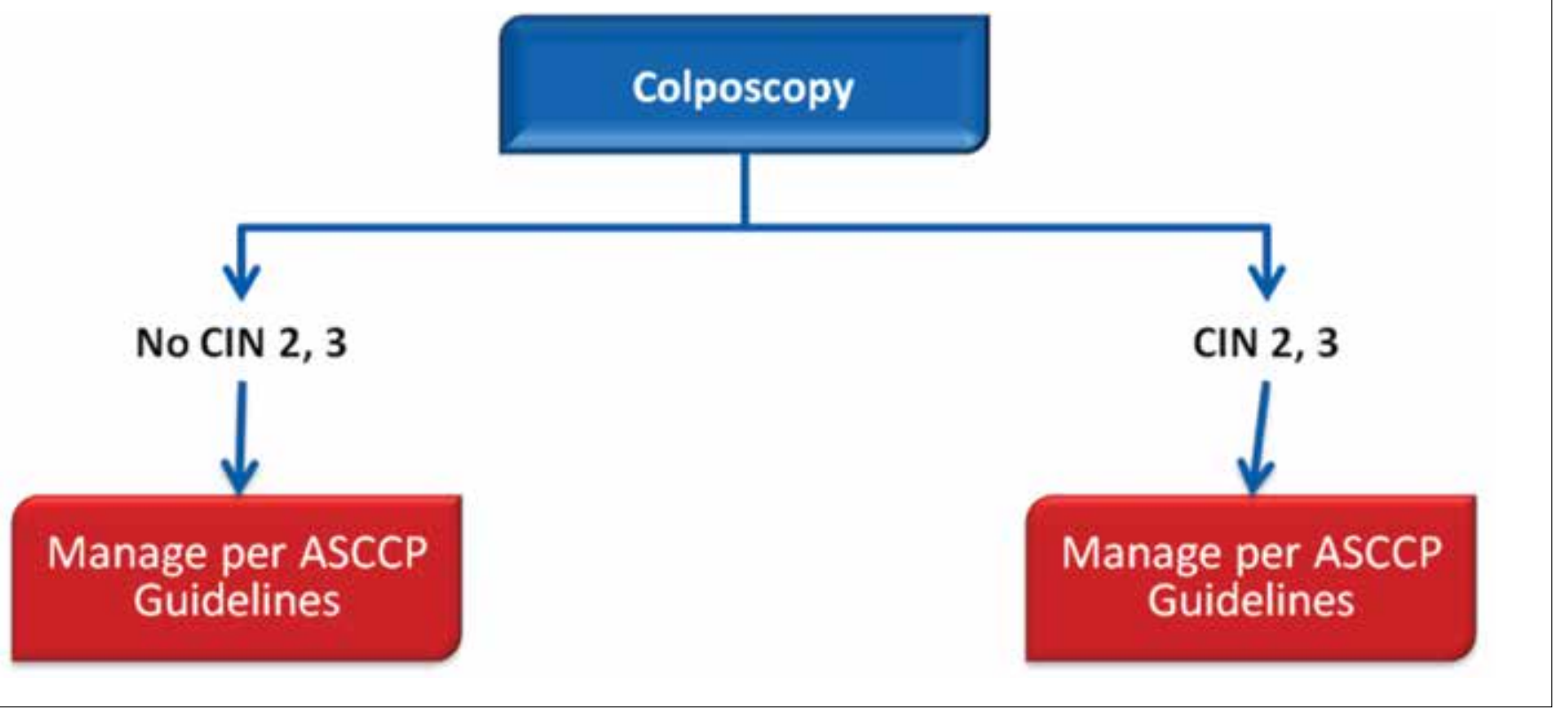

Figure 8. ASC-H management

women with HPV-negative ASC-H is $2 \%$, which is too high to justify observation (Figure 8, 9).

\section{F. HGSIL}

It should be treated. Laser or loop, which has equal success, can be applied. Cold-knife conization is one the methods. Unsuccessful results are due to non-compliance with the protocol. The skill and knowledge of the gynecologist are more important for the success than the method (21-24). Endocervical assessment is important here. HPV testing can be useful in the follow-up; however, it will not be as important as it is for LGSIL.
Colposcopy constitutes one of the main steps. Biopsy will be necessary in the presence of abnormal colposcopic findings, and the treatment of the lesion will be based accordingly (Figure 9, 10). In 2013, the ASCCP published 2012 consensus results about CINs based on the histological diagnosis following the consensus regarding the management of cervical cytological abnormalities (25). The recommendation for CIN 1 is followup without treatment. However, treatment is also an acceptable option. In the follow-up without treatment, in addition to HPV DNA testing, one of the options, which are cytology and colposcopy, can be used. The related flow-chart is presented 


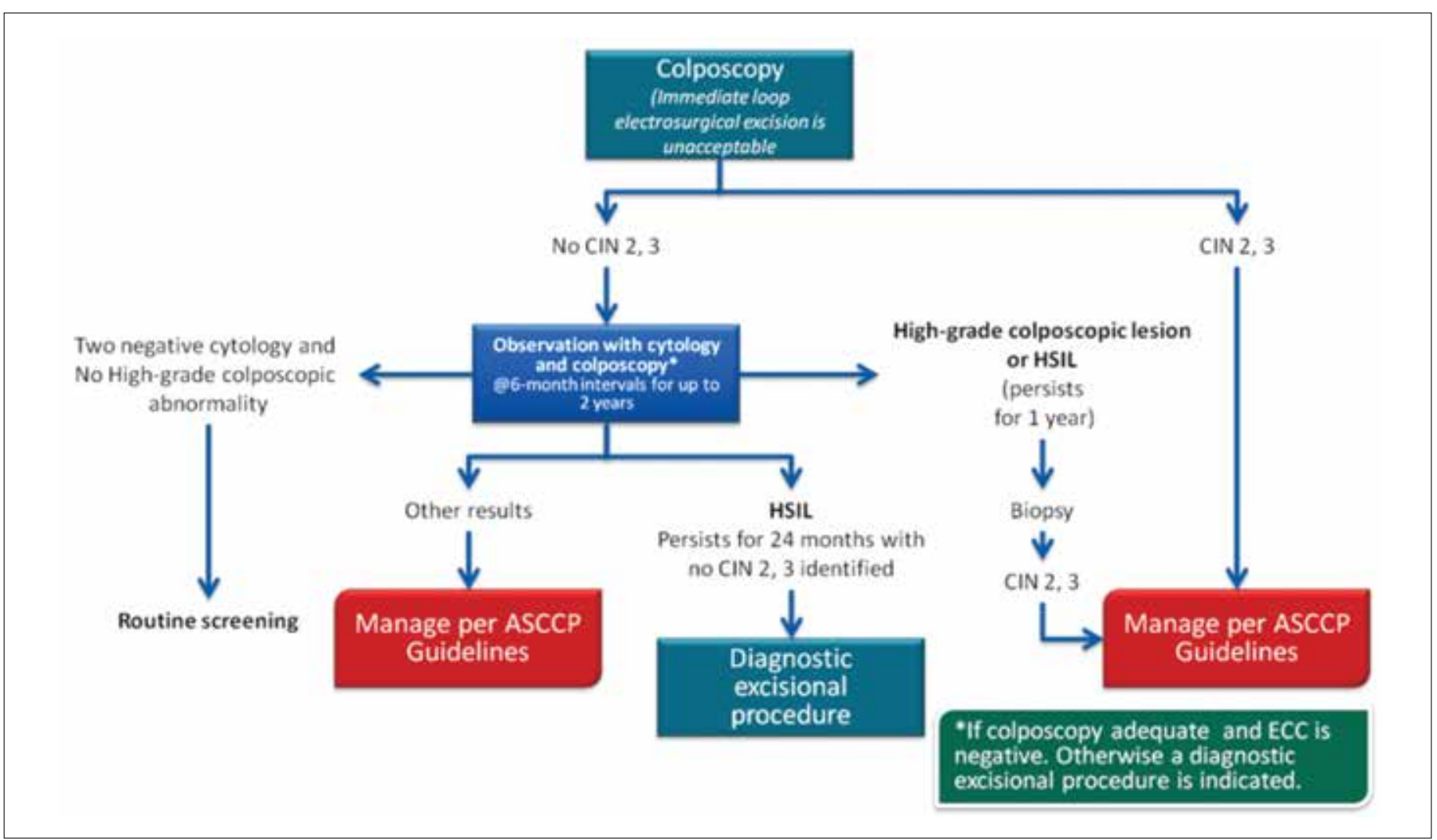

Figure 9. ASC-H and HSIL management between 21-24 years of age

\section{Immediate loop electrosurgical excision*}

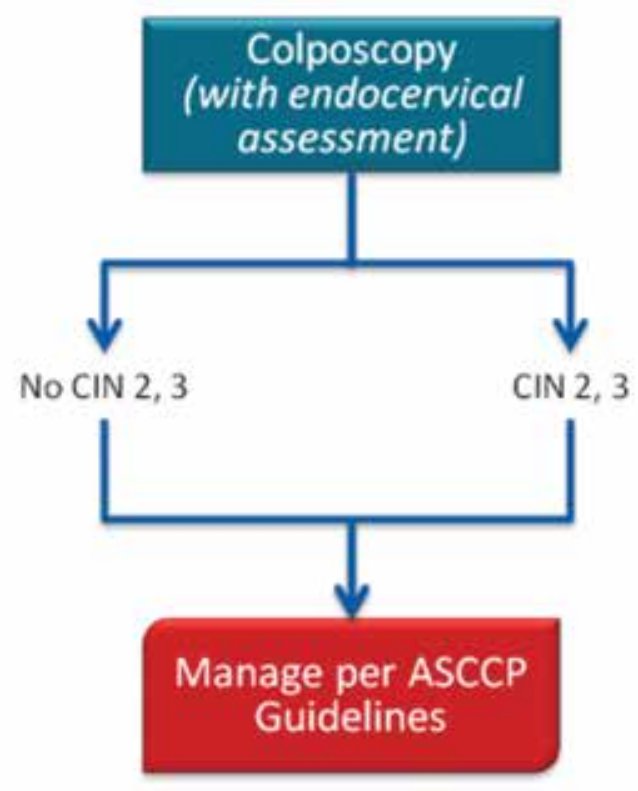

*Management is different for 21 - 24 years of age 


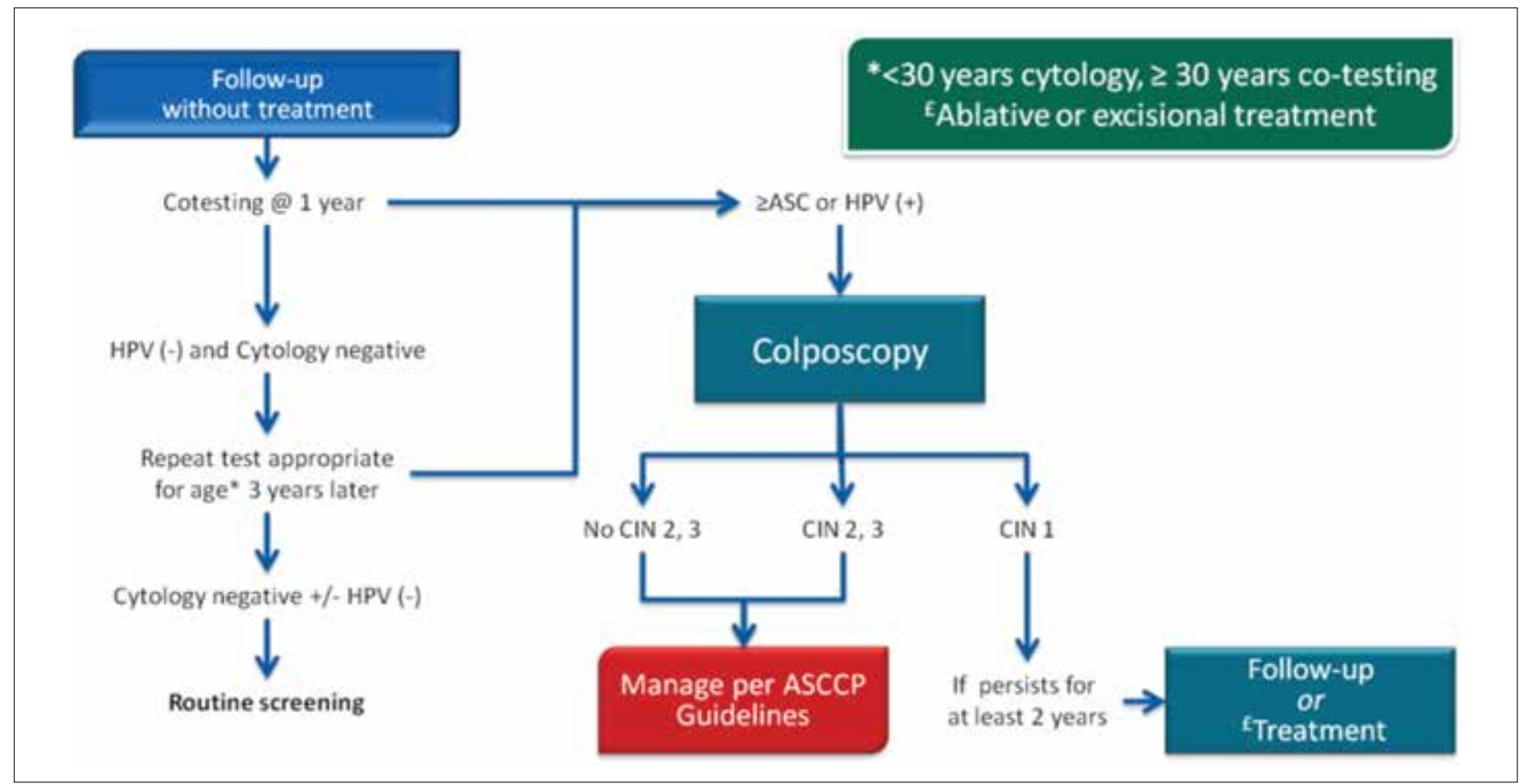

Figure 11. CIN 1 (with ASC-US or LGSIL cytology, HPV16/18(+) or persistent HPV) management
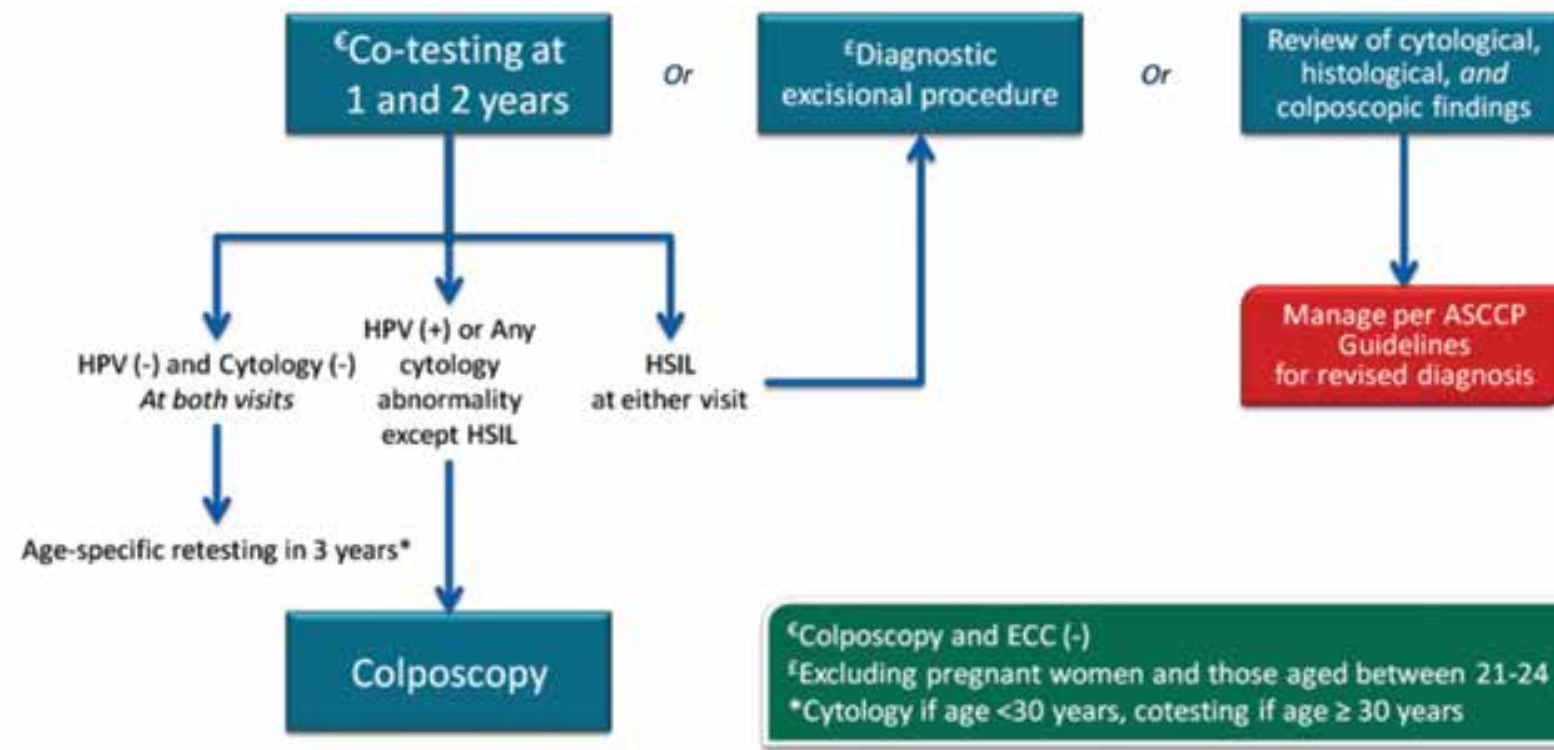

Colposcopy and ECC (-)

'Excluding pregnant women and those aged between $21-24$ years *Cytology if age $<30$ years, cotesting if age $\geq 30$ years

Figure 12. CIN 1 (with ASC-H or HGSIL cytology) management

in Figures 11-13. For the treatment, ablative therapies or excisional procedures (LEEP or cold conization) can be selected. Excisional procedures are necessary for recurrent CIN 1, and it is preferred for the diagnosis of co-existing high-grade lesions, as it provides histological diagnosis. If colposcopy is unsatisfactory, diagnostic excisional biopsy is necessary. However, for pregnant women, adolescents, and patients taking immunosuppressive agents, with unsatisfactory colposcopy, follow-up without treatment is recommended. The treat- ment schema for CIN 2 and 3 confirmed by biopsy is shown in Figures 14 and 15. Although ablative therapy is an acceptable option in this group of patients with adequate colposcopy, excisional therapies should be preferred for recurrent cases. As excisional procedures may cause complications, such as excessive bleeding and risk for preterm delivery in pregnant women with CIN 2 and 3, it should be performed only in patients with suspicion of invasive cancer. Twice-a-week 5 -fluorouracil (5-FU) cream is reported to be the most effec- 


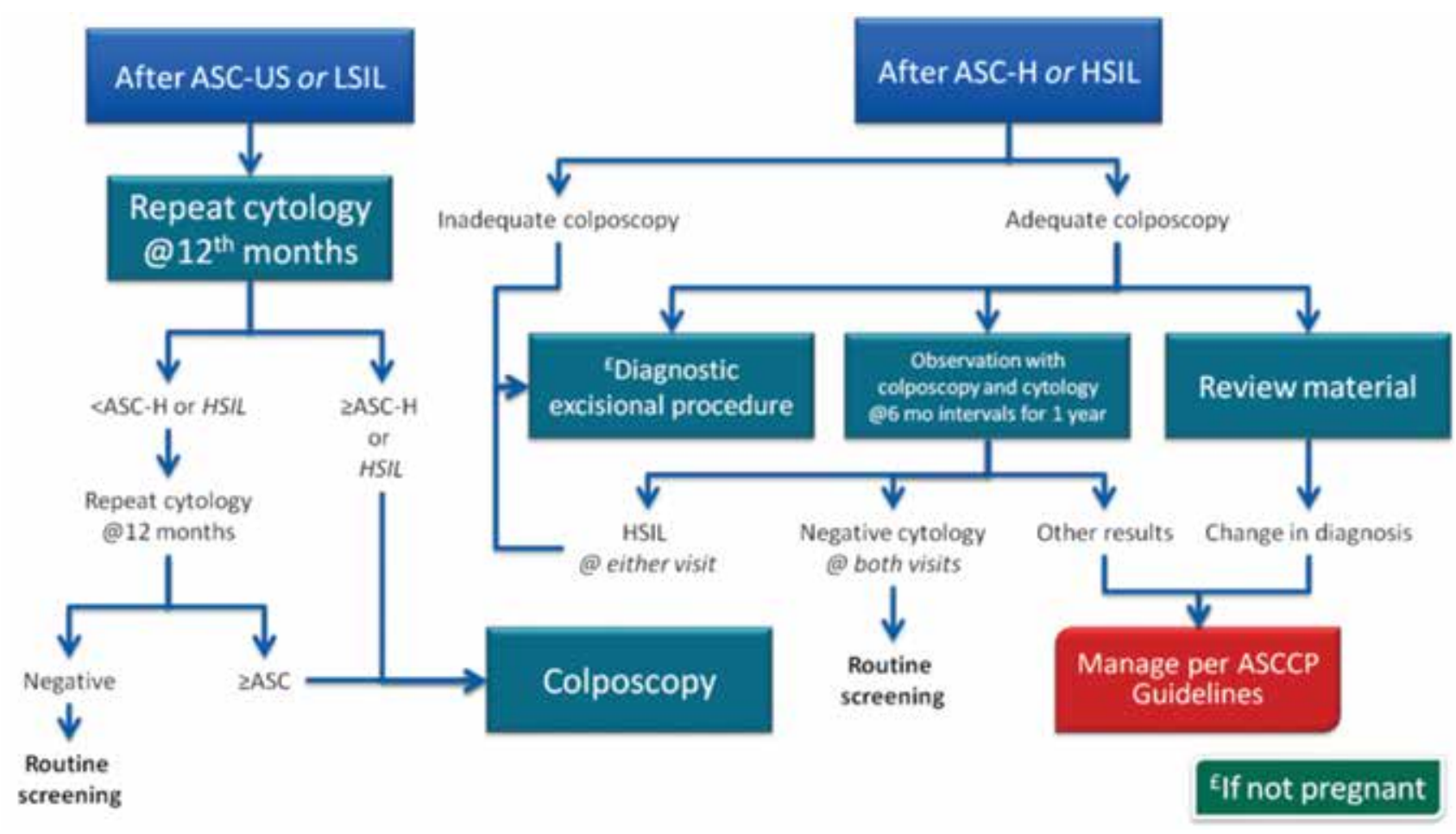

Figure 13. CIN 1 management of cases at 21-24 years of age

In case of adequate colposcopy, observation or treatment can be acceptable.

In CIN 2 diagnosis, preferably observation is recommended;

and in case of CIN 3 or inadequate colposcopy, treatment is recommended.

\section{Observation - Colposcopy and Cytology \\ @6 months intervals for 12 months}

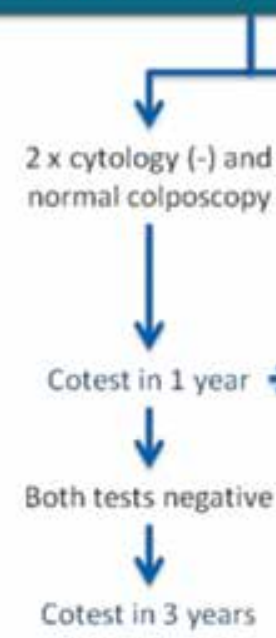

\section{Treatment using Excision or}

Ablation of T-zone
CIN 3 or;

Repeat

Either test abnormal

Colposcopy/Biopsy Recommended
Colposcopy worsens or

High grade cytology or

Colposcopy persists for 1 year

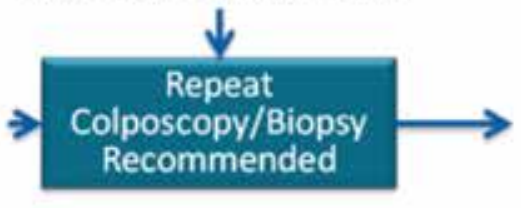

\section{CIN}

CIN 2, 3 persists for 24 months

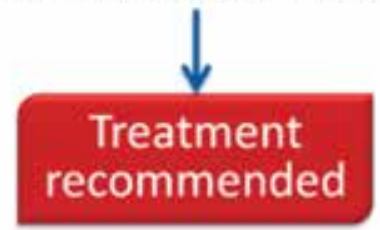

Figure 14. Management CIN 2-3 cases between 21-24 years of age 


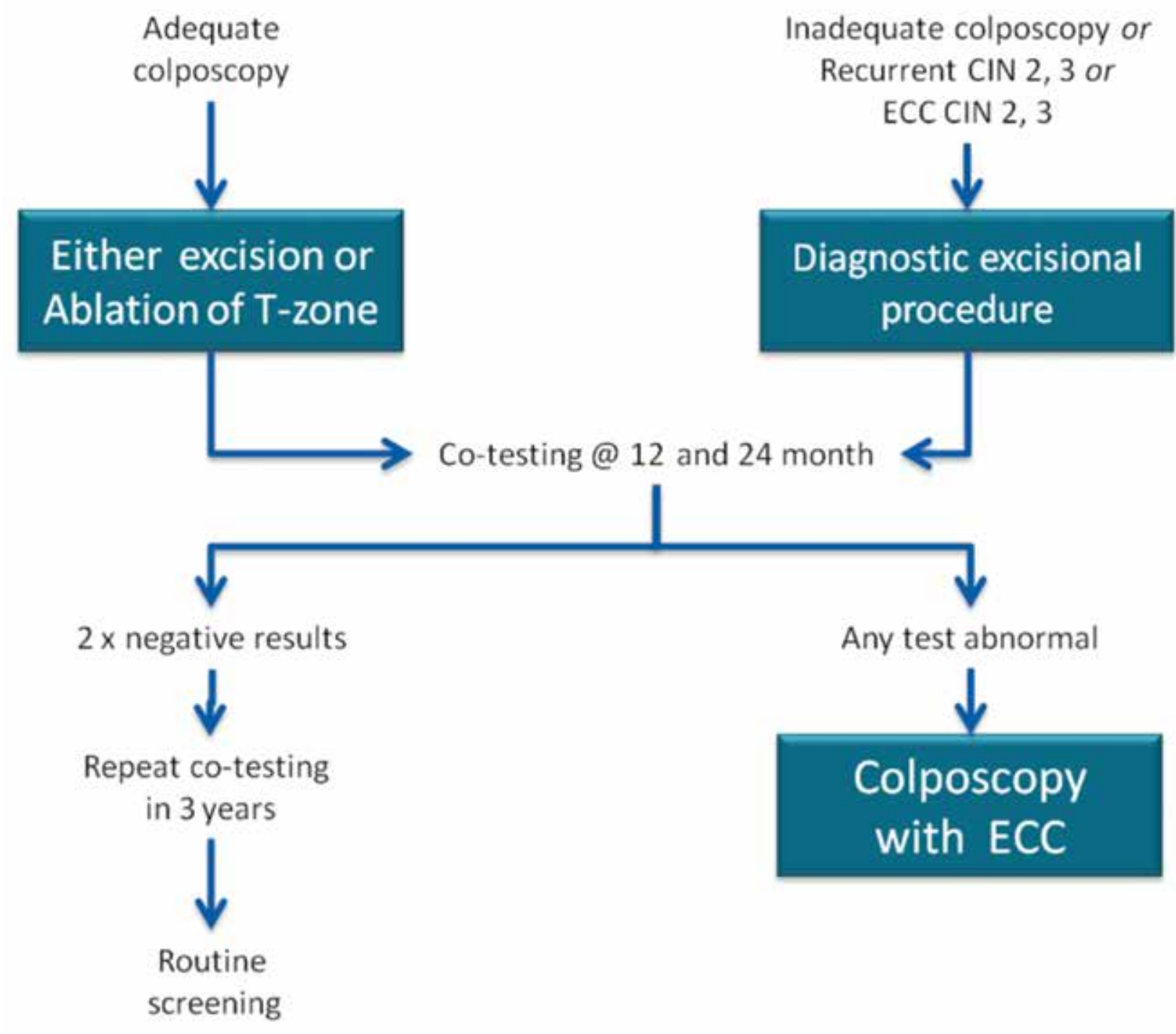

Figure 15. CIN 2-3 management of pregnant cases who are not between 21-24 years of age

tive treatments in HIV (+) patients using immunosuppressive agents (25). Follow-up is more recommended for adolescents with CIN 2, as it is in CIN 1.

\section{Glandular cell abnormalities}

\section{A. Atypical glandular cells (AGC)}

Atypical glandular cells have been associated with polyps and metaplasia but also with neoplasias, including adenocarcinomas of the endometrium, cervix, ovary, fallopian tube, and other sites. Although the cancer risk is lower in women younger than 35 years of age, the risk of CIN 2 and higher lesions is increased at all ages (26). AGC cytology is most commonly associated with squamous lesions, including CIN 1. For women with all subcategories, except atypical endometrial cells, colposcopy with endocervical sampling is recommended in all subcategories. Endometrial sampling is recommended in women 35 years of age and older or with abnormal bleeding in all subcategories. The treatment algorithm is presented in Figures 16 and 17.

\section{B. Adenocarcinoma in situ}

In adenocarcinoma in situ (AIS), endocervical glandular cells are replaced by nuclear stratification, hyperchromasia, irregularities, and long columnar cells with increased mitotic activity (27-29). Cell proliferation leads to overcrowded and punched glands. However, the normal branching pattern of the endocervical glands is reached as well. Most neoplastic cells resemble those of the endocervical mucinous epithelium. Endometrioid and intestinal cell types appear less often. Squamous CIN is observed in 50\% of the women with cervical AIS. So, some of the AIS lesions represent the findings in the samples obtained for squamous neoplasia treatment. As AIS is near or above the transformation zone, traditional cervical samples may not be effective in AIS sampling. Sampling via Cytobrush may enhance AIS screening. If the AIS focus is small, the findings of cervical biopsy and endocervical curettage may be negative. A more comprehensive cervical examination in conization form is necessary for such cases. With such a sample, it is also possible to exclude invasive adeno- 


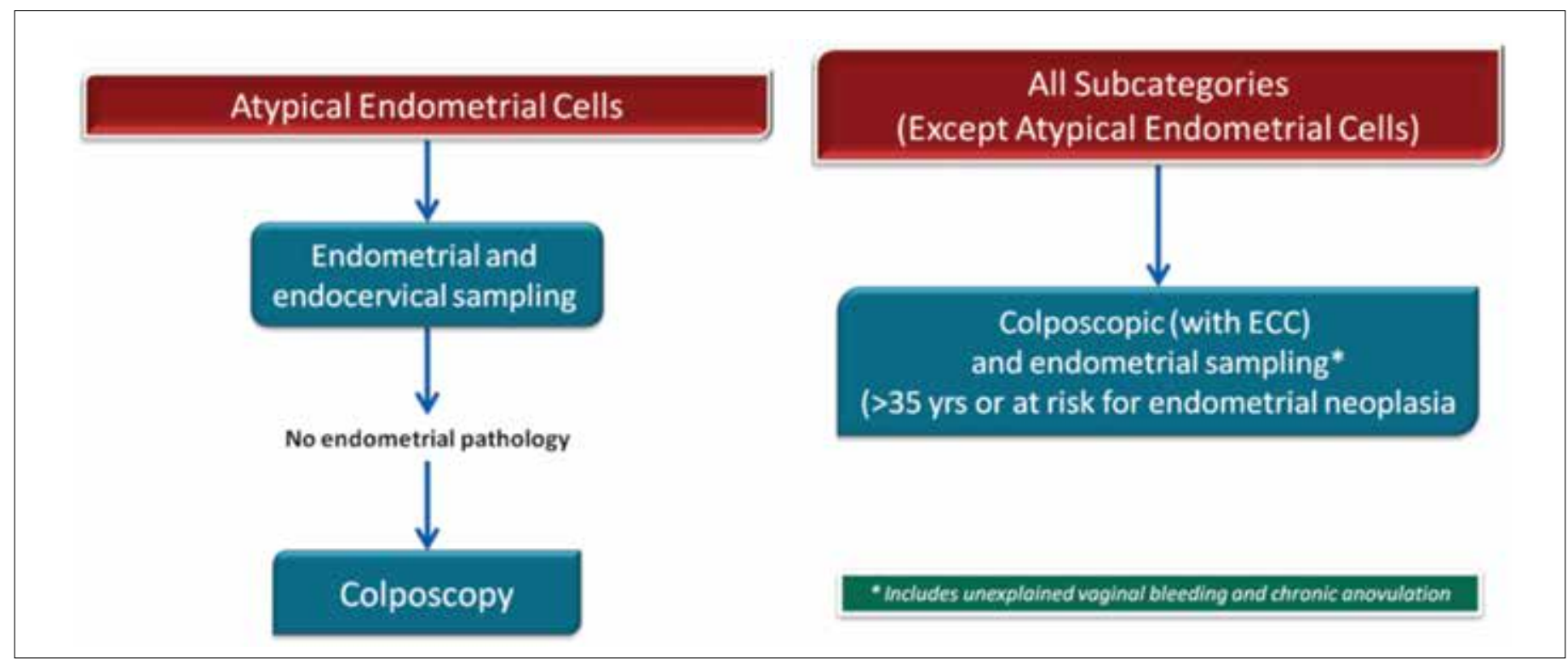

\section{Figure 16. AGC management}

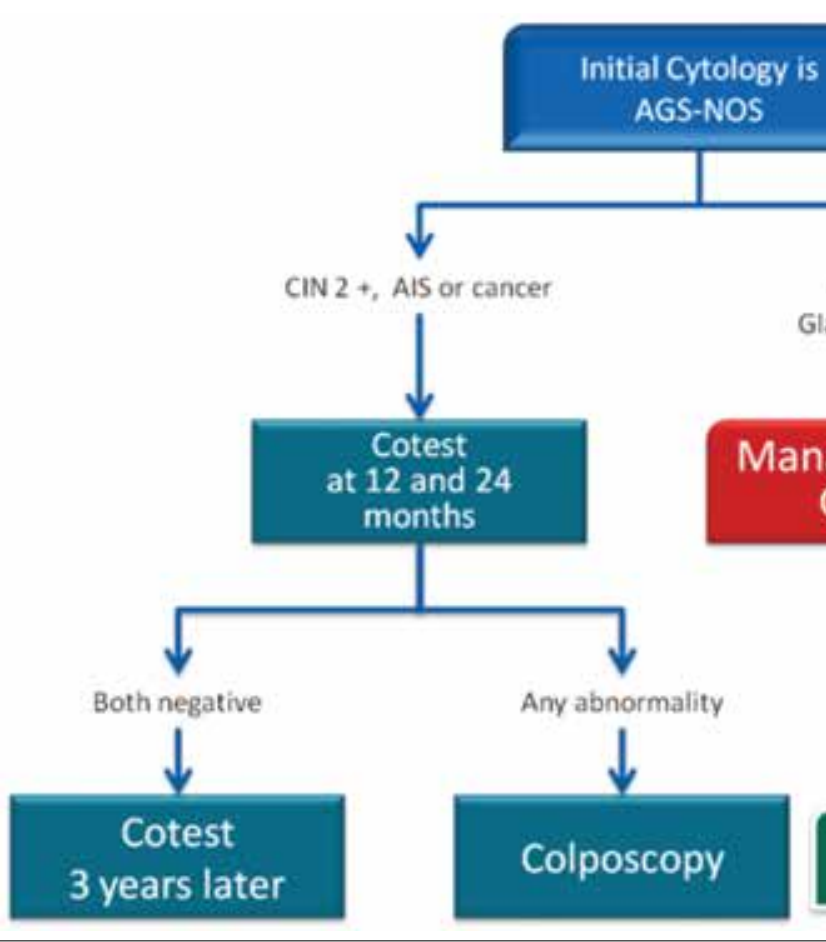

Figure 17. Post-AGC case management

carcinoma. The term "microinvasion" should not be used in adenocarcinoma definitions. Once it spreads to glands, there is no clear technique to determine the true "depth of invasion," because the invasion may have originated from the mucosal surface or from exterior surface of the glands. "Passing" through the basal membrane can not be described completely; therefore, the tumor is either adenocarcinoma in situ or invasive adenocarcinoma.

With the recent increase in endocervical invasive adenocarcinoma, adenocarcinoma in situ has been noticed more. There is evidence that adenocarcinoma in situ can progress to cancer. Boone (30) reported 52 cervical adenocarcinoma cases where 18 endocervical biopsy results were interpreted as negative 3-7 years before cancer developed. Adenocarcinoma was detected among five of them.

Muntz (31) reported 40 cases with AIS who also had cervical conization. Coexisting squamous cell carcinoma was observed in $23(53 \%)$ of these 40 patients. In 10 of the 22 patients who had undergone hysterectomy, margins of coni specimens were positive and $70 \%$ had remaining AIS. Additionally, two patients 


\section{Hysterectomy preferred}

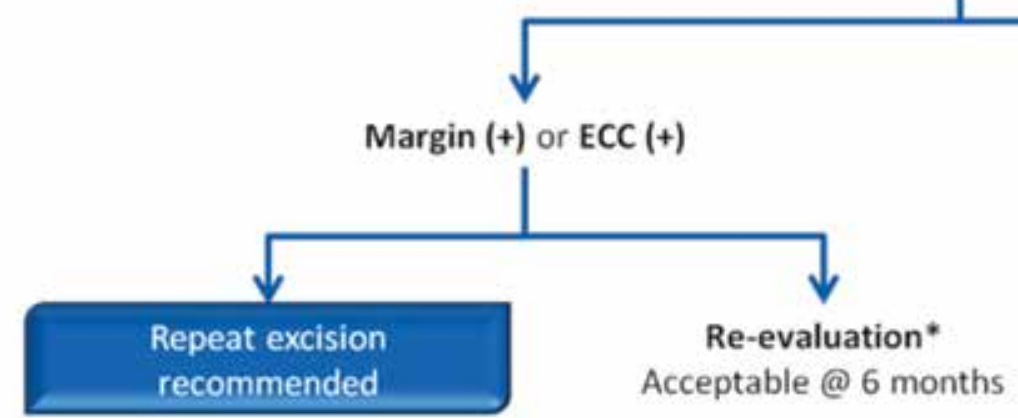

Figure 18. AIS management

had invasive adenocarcinoma. Among the 12 patients with negative margins, focal adenocarcinoma in the hysterectomy specimen was seen in one of them. In 18 women, only conization with negative margins was detected, and the disease did not recurr after 3 years on average. So, positive margins in conization specimens were significant findings for these patients.

Pyonor et al. (32) reported the results of another more interesting study of 28 patients with AIS. Among the 8 patients with positive margins who had undergone repeat conization or hysterectomy, residual AIS was detected in 3 and invasive adenocarcinoma was detected in 1 . Of the 10 patients with negative margins who had undergone hysterectomy or repeat conization, 4 had residual AIS. Invasive adenocarcinoma was detected in 1 patient, whose cone margin had not been examined. Among 15 patients treated with repeat cervical conization and close follow-up, recurrent glandular lesions, detected as a result of conization, were found in 7 patients (47\%), and in 2 of them, invasive adenocarcinoma was detected. Furthermore, $48 \%$ of the patients were not suspected to have glandular lesions based on their endocervical curettage and Pap smear test results obtained before conization.

Adenocarcinoma in situ has to be regarded as a significant adenocarcinoma cancer precursor. The entire endocervical canal is under risk, and examination of lesion by cytology and curettage procedures may be unreliable. Repeat conizations should be performed in patients with positive cone margins. If fertility can be disregarded, hysterectomy should be done, even in the case of a negative margin due to the risk of recurrence (Figure 18).

The NCCN Guidelines Panel for Cervical Cancer Screening endorses the 2012 updated consensus guidelines for the management of abnormal cervical cancer screening tests and cancer precursors (25).

\section{Evaluation of Intraepithelial Lesions During Pregnancy}

Cervical cancer is the most common malignancy during pregnancy. It is relatively rare in developed countries. It is due to the low cancer incidence, depending on low birth rate and routine cervical cytological screening programs. Its incidence is $1-13 / 10,000$. This equals the incidence of 1 cervical cancer in 2000-2500 pregnancies and 1 CIN 3 in 750 pregnancies. Pregnancy was present in about $1 \%$ of the women with cervical cancer at the time of diagnosis. Most of the cases are asymptomatic. Therefore, the diagnosis is often delayed. Patients who experience vaginal bleeding during pregnancy and those with post-coital bleeding should be screened for cervical cancer, and speculum examination should definitely be performed in these patients. Pregnancy does not affect the prognosis of cervical cancer $(33,34)$.

The cervix is soft and hypertrophic during pregnancy and usually moves towards the columnar epithelial porsio. Therefore, unsatisfactory cytology and colposcopy are rare. In the study of Baldauf et al. (35) regarding the management of 140 pregnant women with abnormal smear results, it was found that colposcopy was adequate in $86 \%$ of the patients, compatible with $69 \%$ biopsy diagnosis, $18 \%$ false positive, and $13 \%$ false negative rates. Biopsy was performed in 115 patients, and bleeding was noted in only 1 patient. They concluded that colposcopy and accompanying biopsy are reliable procedures in the management of abnormal smears.

Further, $86 \%$ of the cervical abnormalities during pregnancy are LGSIL, and most of them are caused by HPV. The remaining $14 \%$ are HGSIL. Hormonal and vascular changes during pregnancy do not interfere with the natural progress of invasive cervical cancer. There is no evidence showing faster progression of CIN to invasive cancer during pregnancy.

In conclusion, it should be noted that the goal during pregnancy is not to diagnose and follow up preinvasive lesions or not to treat 
these lesions. The main goal during this period is to detect the presence of invasive lesions, especially during the first half of the pregnancy.

Ethics Committee Approval: N/A.

Informed Consent: $N / A$.

Peer-review: Internally peer-reviewed.

Author contributions: The authors contributed equally during the preparation of this manuscript.

Conflict of Interest: No conflict of interest was declared by the authors.

Financial Disclosure: The authors declared that this study has received no financial support.

\section{References}

1. Vergote I, van der Zee AG, Kesic V, Sert B, Robova H, Rob L, et al. ESGO statement on cervical cancer vaccination. Int J Gynecol Cancer 2007; 17: 1183-5. [CrossRef]

2. Eser SY, Karakoc H. Cancer Incidence in Turkey. In: Tuncer M. Cancer Control in Turkey. Ankara: Ministry of Health; 2010. p. 35-50.

3. de Sanjose S, Quint WG, Alemany L, Geraets DT, Klaustermeier $\mathrm{JE}$, Lloveras B, et al. Human papillomavirus genotype attribution in invasive cervical cancer: a retrospective cross-sectional worldwide study. Lancet Oncol 2010; 11: 1048-56. [CrossRef]

4. Usubutun A, Alemany L, Kucukali T, Ayhan A, Yüce K, de Sanjosé S, et al. Human papillomavirus types in invasive cervical cancer specimens from Turkey. Int J Gynecol Pathol 2009; 28: 541-8. [CrossRef]

5. Parkin DM, Bray F. Chapter 2: The burden of HPV-related cancers. Vaccine 2006; 24 (Suppl 3): S11-25. [CrossRef]

6. Koutsky LA. Epidemiology of genital human papillomavirus infection. Am J Med 1997; 102 (Suppl 1): S3-8. [CrossRef]

7. de Sanjosé S, Diaz M, Castellsagué X, Clifford G, Bruni L, Muñoz N Bosch FX. Worldwide prevelance and genotype distribution of cervical human papillomavirus DNA in women with normal cytology: A meta-analysis. Lancet Infect Dis 2007; 7: 453-9. [CrossRef]

8. Peto J, Gilham C, Deacon J, Taylor C, Evans C, Binns W, et al. Cervical HPV infection and neoplasia in a large population-based prospective study: the Manchester cohort. Br J Cancer 2004; 91: 942-53.

9. Tabbara SO, Sidawy MK. Evaluation of the 5 year review of negative cervical smears in patients with HGSIL. Diagn Cytopathol 1996; 14: 84-6. [CrossRef]

10. Sherman ME, Schiffman M, Herrero R, Kelly D, Bratti C, Mango LJ, et al. Performance of a semiautomated Papanicolaou smear screening system: results of apopulation based study conducted in Guanacaste, Costarica. Cancer 1998; 84: 273-80. [CrossRef]

11. Gay JD, Donaldson LD, Goellner JR. False negative results in cervical cytologic studies. Acta Cytol 1985; 29: 1043-6.

12. Bleckert PO. Prevalance of HPV in cytologic normal smears determined by PCR. Int Cancer 1993; 53: 912-23.

13. Almonte M, Ferreccio C, Winkler JL, Cuzick J, Tsu V, Robles S, et al. Cervical screening by VIA, HPV testing, liquid-based and conventional cytology in Amazonian Peru. Int J Cancer 2007; 121: 796-802. [CrossRef]

14. Moriarty AT, Clayton AC, Zaleski S, Henry MR, Schwartz MR, Eversole GM, et al. Unsatisfactory reporting rates: 2006 practices of participants in the College of American Pathologists interlaboratory comparison program in gynecologic cytology. Arch Pathol Lab Med 2009; 133: 1912-6.

15. Hoda RS, Loukeris K, Abdul-Karim FW. Gynecologic cytology on conventional and liquid-based preparations: A comprehensive review of similarities and differences. Diagn Cytopathol 2012; 41: 257-78. [CrossRef]

16. Siebers AG, Klinkhamer PJJM, Vedder JEM, Arbyn M, Bulten J. Causes and relevance of unsatisfactory and satisfactory but limited smears of liquid-based compared with conventional cervical cytology. Arch Pathol Lab Med 2012; 136: 76-83. [CrossRef]

17. Huang A, Quinn M, Tan J. Outcome in women with no endocervical component on cervical cytology after treatment for high-grade cervical dysplasia. Aust N Z J Obstet Gynaecol 2009; 49: 426-8. [CrossRef]

18. Michell H, Hocking J, Saville M. Cervical cytology screening history of women diagnosed with adenocarcinoma in situ of the cervix: A case-control study. Acta Cytol 2004; 48: 595-600. [CrossRef]

19. Saslow D, Solomon D, Lawson HW, Killackey M, Kulasingam SL, Cain $\mathrm{J}$, et al. American Cancer Society, American Society for Colposcopy and Cervical Pathology, and American Society for Clinical Pathology screening guidelines for the prevention and early detection of cervical cancer. CA Cancer J Clin 2012; 62: 147-72. [CrossRef]

20. Katki HA, Kinney WK, Fetterman B, Lorey T, Poitras NE, Cheung L, et al. Cervical cancer risk for women undergoing concurrent testing for human papillomavirus and cervical cytology: a population-based study in routine clinical practice. Lancet Oncol 2011; 12: 663-72. [CrossRef]

21. Massad LS, Collins YC, Meyer PM. Biopsy correlates of abnormal cervical cytology classified using the Bethesda system. Gynecol Oncol 2001; 82: 516-22. [CrossRef]

22. Alvarez RD, Wright TC. Effective cervical neoplasia detection with a novel optical detection system: a randomized trial. Gynecol Oncol 2007; 104: 281-9. [CrossRef]

23. Dunn TS, Burke M, Shwayder J. A "see and treat" management for high grade squamous intraepithelial lesion Pap smears. J Lower Gen Tract Dis 2003; 7: 104-6. [CrossRef]

24. Katki HA, Schiffman M, Castle PE, Fetterman B, Poitras NE, Lorey $\mathrm{T}$, et al. Five-year risk of cervical cancer and CIN3 for HPV-positive and HPV-negative high-grade Pap results. J Low Genit Tract Dis 2013; 17 (5 Suppl 1): S50-5. [CrossRef]

25. Massad LS, Einstein MH, Huh WK, Katki HA, Kinney WK, Schiffman, et al. 2012 updated concensus guidelines forthe management of abnormal cervical cancer screening tests and cancer precursors. J Low Genit Tract Dis 2013; 17 (5 Suppl 1): S1-27. [CrossRef]

26. Zhao C, Florea A, Onisko A, Austin RM. Histologic follow-up results in 662 patients with Pap test findings of atypical glandular cells: results from a large academic womens hospital laboratory employing sensitive screening methods. Gynecol Oncol 2009; 114: 383-9. [CrossRef]

27. Sharpless KE, Schnatz PF, Mandavilli S, Greene JF, Sorosky JI. Dysplasia associated with atypical glandular cells on cervical cytology. Obstet Gynecol 2005; 105: 494-500. [CrossRef]

28. Castle PE, Fetterman M, Poitras N, Lorey T, Shaber R, Kinney W. Relationship of atypical glandular cell cytology, age and human papillomavirus detection to cervical and endometrial cancer risks. Obstet Gynecol 2010; 115: 243-8. [CrossRef]

29. Simsir A, Carter W, Elgert P, Cangiarella J. Reporting endometrial cells in women 70 years and older: assessing the clinical usefulness of Bethesda 2001. Am J Clin Pathol 2005; 123: 571-5. [CrossRef]

30. Boone ME, Baak JPA, Kurver JPH, Overdierp AH, Verdonk GW. Adenocarcinoma insitu of the cervix: an under-diagnosed lesion. Cancer 1981; 48: 768-73. [CrossRef]

31. Muntz HG, Bell DA, Lage JM, Goff BA, Feldman S, Rice LW. Adenocarcinoma in situ of the uterine cervix. Obstet Gynecol 1992; 80: 935-9.

32. Pyonor EA, Barakat RR, Hoskins WJ. Management and follow up of patients with adenocarcinoma in situ of the uterine cervix. Gynecol Oncol 1995; 57: 158-64. [CrossRef]

33. Kashimura M, Matsuura Y, Shinohara M. Comporative Study of cytology and Punch Biopsy in Cervikal Intra-epithelial NeoplasiaDuring Pregnancy. Acta Cytologica 1991; 35: 100-4.

34. La Polla JP, O'Neill C. Colposcopic management of abnormal cervical cytology in pregnancy. J Reprod Med 1988; 33: 301-6.

35. Baldauf SS, Preysuf M, Goos Ritter S, Philippe E. Management of pregnant woman with abnormal cervical smears (A series of 146 patients). J Gynecology Obstetrics Biological Reproduction (Paris) 1996; 25: 582-7. 